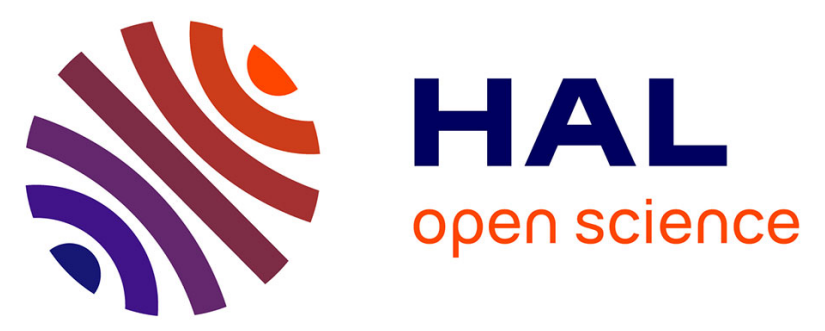

\title{
Highly sensitive and rapid determination of sunset yellow in drinks using a low-cost carbon material-based electrochemical sensor
}

Quang Thuan Tran, Thi Tinh Phung, Quang Trung Nguyen, Truong Giang Le, Corinne Lagrost

\section{To cite this version:}

Quang Thuan Tran, Thi Tinh Phung, Quang Trung Nguyen, Truong Giang Le, Corinne Lagrost. Highly sensitive and rapid determination of sunset yellow in drinks using a low-cost carbon materialbased electrochemical sensor. Analytical and Bioanalytical Chemistry, 2019, 411 (28), pp.7539-7549. 10.1007/s00216-019-02155-9 . hal-02364877

\section{HAL Id: hal-02364877} https://hal-univ-rennes1.archives-ouvertes.fr/hal-02364877

Submitted on 21 Feb 2020

HAL is a multi-disciplinary open access archive for the deposit and dissemination of scientific research documents, whether they are published or not. The documents may come from teaching and research institutions in France or abroad, or from public or private research centers.
L'archive ouverte pluridisciplinaire HAL, est destinée au dépôt et à la diffusion de documents scientifiques de niveau recherche, publiés ou non, émanant des établissements d'enseignement et de recherche français ou étrangers, des laboratoires publics ou privés. 


\title{
Highly sensitive and rapid determination of sunset yellow in drinks using a low-cost carbon material-based
}

\author{
electrochemical sensor
}

Quang Thuan Tran, ${ }^{* a}$ Thi Tinh Phung, ${ }^{a}$ Quang Trung Nguyen, ${ }^{a}$ Truong Giang Le,${ }^{b}$ Corinne Lagrost,$* c$

a Vietnam Academy of Science and Technology (VAST), Center for Research and Technology Transfer (CRETECH), 18 Hoang Quoc Viet, Hanoi, Vietnam

b Vietnam Academy of Science and Technology (VAST), Institute of Chemistry, 18 Hoang Quoc Viet, Hanoi, Vietnam

c Univ. Rennes, CNRS, Institut des Sciences Chimiques de Rennes, UMR 6226, Campus Beaulieu, 35042 Rennes Cedex, France

* E-mail: tranquangthuan2008@gmail.com and corinne.lagrost@univ-rennes1.fr

\begin{abstract}
Starting from simple graphite flakes, an electrochemical sensor for sunset yellow monitoring is developed by using a very simple and effective strategy. The direct electrochemical reduction of a suspension of exfoliated graphene oxide (GO) onto a glassy carbon electrode (GCE) surface leads to the electrodeposition of electrochemically reduced oxide at the surface, obtaining GCE/ERGO-modified electrodes. They are characterized by cyclic voltammetry measurements $(\mathrm{CV})$ and field emission scanning electron spectroscopy (FE-SEM). The GCE/ERGO electrode has a high electrochemically active surface allowing efficient adsorption of SY. Using differential pulse voltammetry (DPV) technique with only 2 min accumulation, the GCE/ERGO sensor exhibits good performance to SY detection with a good linear calibration for concentration range varying $50-1000 \mathrm{nM}\left(\mathrm{R}^{2}=0.996\right)$ and limit of detection (LOD) estimated to $19.2 \mathrm{nM}$ (equivalent to $8.9 \mu \mathrm{g} . \mathrm{L}^{-1}$ ). The developed sensor possesses a very high sensitivity of $9 \mu \mathrm{A} / \mu \mathrm{M}$ while fabricated with only one component. This electrochemical sensor also displays a good reliability with RSD value of $2.13 \%(\mathrm{n}=7)$ and excellent reusability (signal response change $<3.5 \%$ after 6 measuring/cleaning cycles). The GCE/ERGO demonstrates a successful practical application for determination of sunset yellow in commercial soft drinks.
\end{abstract}

Keywords: Graphene oxide, electrochemical deposition, electrochemical sensor, sunset yellow detection, sensitivity, reusability

\section{Introduction}

Synthetic dyes are usually added to foodstuff and soft drinks not only for improving appearance and texture but also for maintaining natural colors during process or storage. Generally, they exhibit higher performances than natural dyes owing to excellent water solubility, charming color uniformity, high stability to light, oxygen and $\mathrm{pH}$, low microbiological contamination and relatively low production costs. They are then largely used in food, but also in cosmetics or drugs, as additives to enhance consumer acceptance. Many of these dyes are based on $-\mathrm{N}=\mathrm{N}$ - diazo functional group combined with aromatic rings. However, an excessive consumption may cause dangerous pathogenic effects including contact urticaria and anaphylaxis, immunosuppression, asthma, eczema, anxiety migraines $[1,2,3,4]$, bladder cancer in men and hepatic carcinoma in mice [5]. As early as 1920 s, they were already related to hyperactivity, hypersensitivities learning problems [6]. Sunset yellow represents one of the most frequently artificial dyes applied into food products. Undoubtedly, the use is controlled by regulations, for instance, an accepted daily intake (ADI) of $4 \mathrm{mg} / \mathrm{kg}$ body/day has been established by the European Food Safety Authority (EFSA) [7]. Some European countries (Finland, Sweden) have even banned its use. In this context, a convenient and effective method is needed for sunset yellow detection in order to control food quality and thus providing safety assurances for consumers. Up-to-date, some methods including UV-VIS [8] fluorescence [9], spectrophotometric [10] and Raman spectroscopy [11], high performance liquid chromatography [12,13,14,15], high performance liquid chromatography-mass spectrometry [16] have been applied to the determination of sunset yellow in foods. However, these methods generally require costly equipment, specially trained operators, tedious sample preparation and /or may have a poor limit of detection. Recently, electrochemical detection method has attracted much attention as a promising approach for the determination of the electrochemically active substances thanks to numerous advantages including rapid response, simple-touse, excellent sensitivity, time efficiency, portable monitoring and relatively low production cost $[17,18]$. Sunset yellow is an electrochemically-active compound and could be practically determined by this way [19]. Some modified 
glassy carbon electrodes were developed for detection of sunset yellow such as poly-L-cysteine modified GCE [20], polypyrrole/single wall carbon nanotube composite modified GCE [21], bismuth film modified GCE [22], functionalized montmorillonite modified GCE [23], ZnO nano-flower modified GCE [24]. Briefly, use of the nanomaterials remarkably enhance sensitivity of electrochemical (bio)sensors owing to their beneficial properties such as high surface-to-area ratio, exceptional physiochemical behaviors, high adsorption and reactive capacity and thus it was extensively applied to foods and environmental analysis $[25,26,27,28]$.

Graphene which is comprised of an atomically thin 2D carbonaceous materials represents an archetypal supporting materials owing to its large specific surface area, excellent conductivity, high catalytic activity, exceptional mechanical properties. Logically, it has attracted interests for sensing application [29,30]. Two main routes could be introduced for the synthesis of graphene materials-based sensors. Firstly, graphene film-based sensors could be achieved by a simple drop-casting of a dispersion of graphene in solution onto conducting surfaces. Such a dispersed solution was commonly prepared from graphene oxide (GO) using chemical reduction $[31,32,33,34]$. However, this preparation method has some intrinsic limitations such as lack of the film thickness control and irreversible agglomerates formation due to strong planar stacking of the $2 \mathrm{D}$ graphene nanosheets. Thus, an alternative method for preparation of more structured graphene films is preferable. Electrochemical reduction from a graphene oxide (GO) dispersed in solution represents a highly potential method to this purpose. This approach could be achieved via two steps, namely: (i) assembling highly dispersed GO onto electrode surface by solution deposition and ii) carrying an electrochemical reduction of deposited GO layers into electrochemically reduced graphene oxide (ERGO) [32,35,36,37,38,39,40]. Recently, a much more straightforward process was proposed using a direct electrochemical reduction of GO solutions into ERGO which is (electro-)deposited onto the electrode surfaces $[41,42,43,44]$. The successfully prepared ERGO electrochemical sensors could be applied for determination of various substances such as phenolic compounds [41,44], biogenic amines [43], dopamine, ascorbic and uric acid $[45,46]$, glucose [47]. However, relatively few graphenebased electrochemical sensors have been developed for electrochemical determination of sunset yellow. Some graphene materials based electrochemical sensors for this purpose could be quoted such as graphene-Ni modified GCE [48], graphene-PTA film modified GCE [49], graphene/AuNPs modified GCE [50]. Most of these sensors require multi-steps and sophisticated preparation, and very often incorporate composite materials or metallic nanomaterials.

Herein, we report the preparation of ERGO modified glassy carbon surface as an electrochemical sensor for monitoring sunset yellow (SY). The preparation strategy is based on a simple and costly-effective process, starting directly from low-cost graphite flakes. The GCE/ERGO electrodes are obtained from the simple electrochemical deposition route, hence demonstrating in full a very robust procedure. Optimization of the preparation of GCE/ERGO electrode along with optimization of the analytical experimental parameters for SY titration are thoroughly performed. The electrochemical behaviour of SY at the GCE/ERGO platform is studied in depth. Finally, the GCE/ERGO is applied to real sample analysis on commercial soft drinks. The obtaining GCE/ERGO show great potential as accurate, low cost, rapid and highly sensitive portable sensor, only based on single component graphene.

\section{Material and methods}

\subsection{Chemicals and instrumentation}

Chemicals of analytical grade were used without any further purification. Graphite flakes (99\%, 325 mesh particle size), lithium perchlorate $\left(\mathrm{LiClO}_{4} 99 \%\right)$, potassium hexacyanoferrate (II) trihydate $\left(\mathrm{K}_{4} \mathrm{Fe}(\mathrm{CN})_{6} .3 \mathrm{H}_{2} \mathrm{O} 98 \%\right)$ and hexacyanoferrate (III) $\left(\mathrm{K}_{3} \mathrm{Fe}(\mathrm{CN})_{6} 99 \%\right)$ were obtained from Sigma Aldrich. Potassium permanganate $\left(\mathrm{KMnO}_{4}\right)$, sulfuric acid $\left(\mathrm{H}_{2} \mathrm{SO}_{4} 98 \%\right)$, phosphoric acid $\left(\mathrm{H}_{3} \mathrm{PO}_{4} 85 \%\right)$, boric acid $\left(\mathrm{H}_{3} \mathrm{BO}_{3}\right.$, 99\%) hydrochloric acid $(\mathrm{HCl} 37 \%)$, sodium hydrophosphate hydrate $\left(\mathrm{Na}_{2} \mathrm{HPO}_{4} .7 \mathrm{H}_{2} \mathrm{O} 99 \%\right)$, sodium dihydrophosphate $\left(\mathrm{NaH}_{2} \mathrm{PO}_{4} \quad 99 \%\right)$, sodium acetate $\left(\mathrm{CH}_{3} \mathrm{COONa} 99 \%\right)$, acetic acid $\left(\mathrm{CH}_{3} \mathrm{COOH} 100 \%\right)$, and solvents (acetone $\mathrm{CH}_{3} \mathrm{COCH}_{3}$ and diethyl ether $\mathrm{Et}_{2} \mathrm{O}$ ) were purchased from Merck. The sunset yellow (90.5\%) standard compound was obtained from LGC standard, Dr.

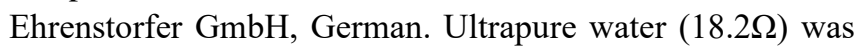
obtained from Milli-Q Integral 3 purification system. Soft drinks (Samurai, Sting, Number 1 and Mirinda) were purchased from a local Hanoi supermarket.

Electrochemical experiments (cyclic voltammetry (CV) and differential pulse voltammetry (DPV) were carried out using a CIMPS electrochemical workstation (Zahnner) with a conventional three-electrode system. The working electrode is either a glassy carbon electrode (GCE of $3 \mathrm{~mm}$ diameter), or a GCE modified with ERGO for sensing experiments, or an ITO plate $\left(2 \times 1 \mathrm{~cm}^{2}\right)$ for SEM analyses. A Pt wire and a saturated calomel reference electrode serve as counter and reference electrodes, respectively.

Morphology of ERGO layer deposited onto ITO surface was characterized using Field Emission scanning electron 
microscopy (FE-SEM, Hitachi S4800). Sunset yellow detection by chromatography method was performed on $\mu$ HPLC instrumentation (Ultimate 3000, Thermo Scientific) equipped with an UV detector.

\subsection{Graphene oxide (GO) preparation}

Graphene oxide (GO) was synthesized from natural graphite flakes following an adapted Hummer method $[51,52]$. Briefly, graphite flakes $(1.0 \mathrm{~g})$ and boric acid $(0.010$ g) were first dispersed into $60 \mathrm{~mL}$ of concentrated $\mathrm{H}_{2} \mathrm{SO}_{4} / \mathrm{H}_{3} \mathrm{PO}_{4}$ mixture $(9 / 1=\mathrm{v} / \mathrm{v})$ maintained in ice-cooling bath with a magnetically stirring. $\mathrm{KMnO}_{4}(3.0 \mathrm{~g}, 3$ wt. equivalent) was slowly added in small portions in the mixture maintained at less than $5^{\circ} \mathrm{C}$, followed by stirring for $1.5 \mathrm{~h}$. Another amount of the $\mathrm{KMnO}_{4}(3.0 \mathrm{~g}$, $3 \mathrm{wt}$ equivalent) was slowly added at less than $5^{\circ} \mathrm{C}$. The mixture was then heated up to $35^{\circ} \mathrm{C}$ while stirring for 3 hours. Deionized water (60 $\mathrm{mL}$ ) was gradually added to the mixture reaction which was heated up to $98^{\circ} \mathrm{C}$ and maintained at this temperature for 15 min. After cooling at room temperature, $\mathrm{H}_{2} \mathrm{O}_{2}$ aqueous solution ( $3 \mathrm{~mL}, 30 \%$ ) was slowly added to quench the reaction. A color change from dark brown to bright yellow occurred. Adding deionized water $(200 \mathrm{~mL})$ afforded a yellow suspension which was decanted through a centrifugation process at $10000 \mathrm{rpm}$ for $6 \mathrm{~min}$. A yellow paste was obtained and washed with aqueous $1 \mathrm{M} \mathrm{HCl}(100 \mathrm{~mL})$ through repeated centrifugations at $7000 \mathrm{rpm}$ for 6 minutes (3 times). A brown solid was obtained, and dried at $60^{\circ} \mathrm{C}$ for 7 hours. Finally, it was re-dispersed in acetone $(20 \mathrm{~mL})$ and precipitated with diethyl ether $(50 \mathrm{~mL})$. The obtained precipitate was filtered using cellulose acetate membrane $(0.45 \mu \mathrm{m})$ under vacuum and thoroughly rinsed with diethyl ether. After drying at $60^{\circ} \mathrm{C}$ for $7 \mathrm{~h}$, the GO was obtained as a brown solid (1.84 g).

\subsection{Electrochemical preparation of the ERGO modified electrodes (GCE/ERGO)}

Before modification, glassy carbon disk electrode was thoroughly polished using DP-Nap polishing paper $1 \mu \mathrm{m}$ (Struers) and $\mathrm{Al}_{2} \mathrm{O}_{3}$ slurry $0.3 \mu \mathrm{m}$ (Struers) to mirror-like surface and then ultra-sonicated for $5 \mathrm{~min}$ in acetone and water, respectively. The polished electrodes were further activated in aqueous $0.5 \mathrm{M} \mathrm{H}_{2} \mathrm{SO}_{4}$ by cycling 5 successive potential scans between 0 and $1.8 \mathrm{~V}$ at the scan rate $\mathrm{v}=50$ $\mathrm{mV} . \mathrm{s}^{-1}$. The GO solid powder was firstly dispersed in deionized water $(8.0 \mathrm{~mL}, 1 \mathrm{mg} . \mathrm{mL}-1)$ by ultra-sonication for $1 \mathrm{~h}$. This suspension was subsequently centrifuged at $500 \mathrm{rpm}$ for $20 \mathrm{~min}$ and decanted for removing unreacted graphite flakes (see Electronic Supplementary Material Fig. S1). The $\mathrm{LiClO}_{4}$ salt was then added to the supernatant, leading to a solution of $\mathrm{GO}$ containing $0.2 \mathrm{M} \mathrm{LiClO}_{4}$ which was sonicated for 15 minutes before electrochemical deposition. The GCE was then immersed in the GO solution under magnetic stirring and Ar bubbling. Successive potential cycles between 0.6 to $-1.5 \mathrm{~V} / \mathrm{SCE}$ were applied for electrodeposition of electrochemically reduced graphene oxide (ERGO).

\subsection{Sample preparation and Detection}

Sunset yellow (SY) standard solution $\left(10^{-4} \mathrm{M}\right)$ were daily prepared from stock solution in deionized water. The electrolyte solutions exhibiting different $\mathrm{pH}$ values were prepared from $0.1 \mathrm{M}$ acetate buffer for $\mathrm{pH}=3,4$ and 5 and $0.1 \mathrm{M}$ phosphate buffer for $\mathrm{pH}=6,7$ and 8 . Before use, the soft drink samples were filtered on KX Nylon membrane syringe (13 mm, $0.22 \mu \mathrm{m}$, Kinesis), being simply diluted in the buffer or deionized water for electrochemical or chromatography analyses, respectively. The DPV signals were recorded from 0 to $0.9 \mathrm{~V} / \mathrm{SCE}$ after $2 \mathrm{~min}$ of accumulation at $0 \mathrm{~V} / \mathrm{SCE}$. Optimal DPV experimental conditions were determined to be $10.5 \mathrm{mV}$ step potential, 20 $\mathrm{mV}$ pulse amplitude, $120 \mathrm{~ms}$ pulse width and scan rate 35 $\mathrm{mV} . \mathrm{s}^{-1}$. Besides, soft drink samples were also determined by HPLC method using RP-C18 column (endcapped $5 \mu \mathrm{m}$, Purospher@STAR, Hibar@RT 250-4.6 mm) for comparison (see ESI).

\section{Results and discussion}

\subsection{Preparation and characterization of the GCE/ERGO sensing electrodes}

The GCE/ERGO electrode was prepared through the electrochemical reduction of GO by employing cyclic voltammetry $(\mathrm{CV})$, following previously described procedure $[41,42,43,44]$. The corresponding voltammograms display the characteristic signals for the electrodeposition of electrochemically reduced graphene oxide (ERGO) at the GCE surface (see Electronic Supplementary Material Fig. S2) [41]. This very simple deposition method can be applied to any conducting surface. The electrodeposition of the ERGO film on surface by CV could be directly confirmed by FESEM image as shown in Fig. 1. The surface morphology presents the typical crumpled lamellar structure of graphene nanosheets. 


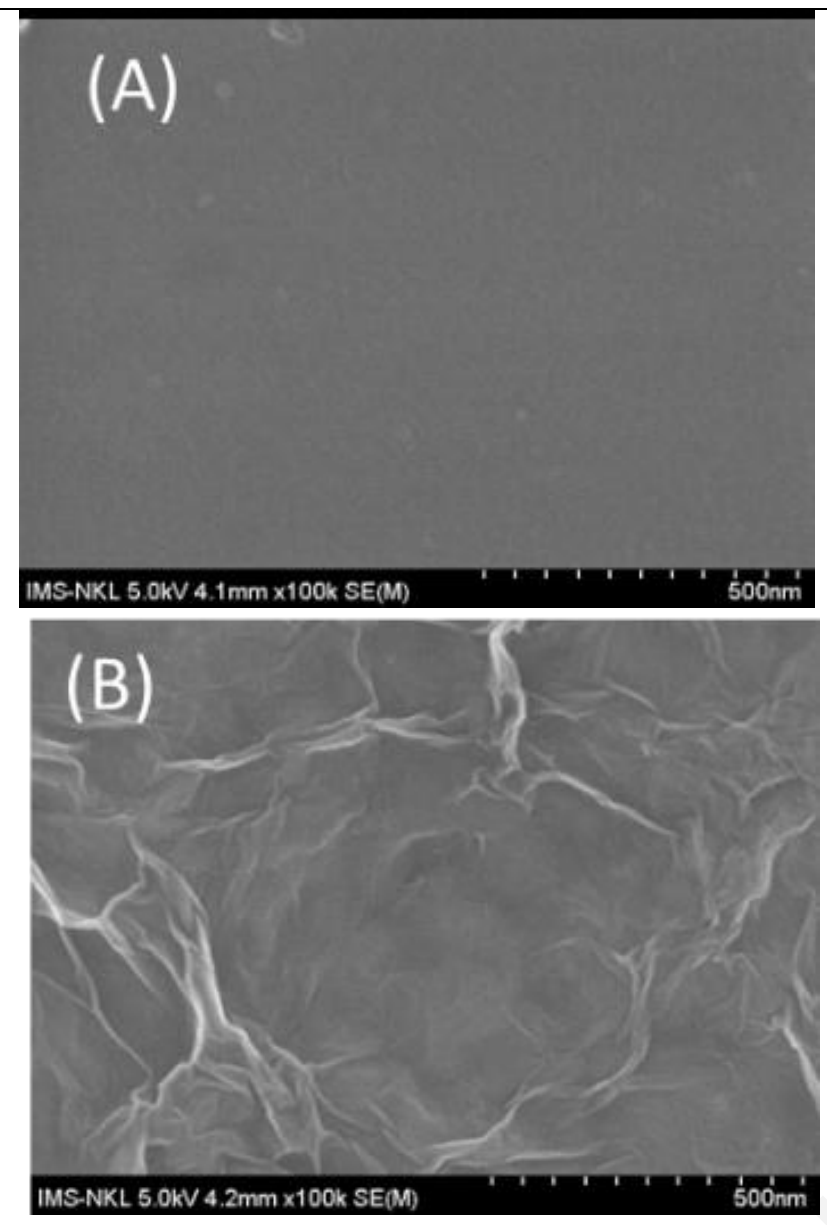

Fig. 1. FE-SEM images of (A) bare pristine ITO and (B) ERGO film electrodeposited onto the ITO surface after 10 potential scanning cycles.

Practically, the number of the potential cycles is an important parameter in view of current sensitivity as it directly correlates with the thickness of graphene film. A true advantage of the electrodeposition technique is the possibility to easily control the thickness of graphene film thanks to the number of potential cycles. In the following, the effect of CVs cycles, namely 5, 10 and 15 scans, was investigated with respect to the electrochemical properties of GCE/ERGO modified electrodes as well as to their sensitivity towards sunset yellow detection.

The electrochemically active area of the modified GCE/ERGO electrodes were determined by recording $\mathrm{CV}$ of equimolar concentration of $\mathrm{K}_{3} \mathrm{Fe}(\mathrm{CN})_{6} / \mathrm{K}_{4} \mathrm{Fe}(\mathrm{CN})_{6}$ in aqueous $\mathrm{KCl}$ compared to bare GCE. The voltamogramms display a well-defined and reversible redox system at both GCE/ERGO and GCE electrodes (see Electronic Supplementary Material Fig. S3). Interestingly, the peak-topeak separation $(\triangle \mathrm{Ep}=\mathrm{Epc-Epa}$, where Epc and Epa are the cathodic and anodic peak potentials, respectively) and the peak current intensities (Ip) were monotonically affected by the surface modification, depending on the number of scans (see Electronic Supplementary Material Fig. S4). A significant increase of the current intensities along with a decrease of $\Delta \mathrm{Ep}$ is observed at GCE/ERGO compared to GCE, and the amplitude of these effects correlates with the number of scans performed during the electrodeposition process. Such an observation falls in line with the modification of GCE surface during reduction in GO solution. The peak-to-peak separation at $50 \mathrm{mV} . \mathrm{s}^{-1}$ is found equal to $110 \mathrm{mV}$ at GCE electrode, $94 \mathrm{mV}, 80$ and $72 \mathrm{mV}$ for GCE/ERGO electrodes prepared with 5, 10, and 15 scans respectively (see Electronic Supplementary Material Table S1), indicating a strong improvement of the electron transfer kinetics at the GCE/ERGO modified surfaces, and especially at the ones obtained with more than 10 scans.

The variation of the intensity of the anodic peak current (Ipa) is linear as a function of the square root of the scan rate $\left(\mathrm{v}^{1 / 2}\right)$ (Electronic Supplementary Material Fig. S4). From the slope of the line, the electrochemically active surface area (A) could be calculated from Randles-Sevcik equation (Eq. 1):

$$
\text { Ipa }=2.69 \times 10^{5} \cdot n^{3 / 2} A \cdot D^{1 / 2} \cdot v^{1 / 2} \cdot C(\text { Eq. } 1)
$$

where Ipa is the peak current intensity (A); $\mathrm{n}$ is the number of electrons exchanged, here $n=1, C$ is the concentration $\left(\mathrm{mol} . \mathrm{cm}^{-3}\right)$ of the redox probe in bulk solution, $\mathrm{D}\left(7.6 \times 10^{-6}\right.$ $\left.\mathrm{cm}^{2} . \mathrm{s}^{-1}\right)$ is the diffusion coefficient, $\mathrm{v}$ the scan rate $\mathrm{v}\left(\mathrm{V} . \mathrm{s}^{-1}\right)$; and $\mathrm{A}$ the surface area $\mathrm{A}\left(\mathrm{cm}^{2}\right)$. Bare GCE electrode has an electrochemically active surface area or ESCA value of 0.069 $\mathrm{cm}^{2}$, in good agreement with the geometric value of 0.071 $\mathrm{cm}^{2}$. As expected, GCE/ERGO surfaces display higher ECSA values, equal to $0.083,0.097$ and $0.115 \mathrm{~cm}^{2}$ corresponding to electrodes prepared with 5; 10 and $15 \mathrm{CV}$ scans, respectively (see Electronic Supplementary Material Table S1). Thus, GCE/ERGO modified surfaces allow increasing the ECSA value up to 1.67 folds using 15 scans modification compared to $\mathrm{GCE}$.

Electrochemical response of sunset yellow (SY) at different GCE/ERGO electrodes were examined using CV and DPV techniques (Fig. 2). The CVs at the GCE/ERGO electrodes show a well-defined and reversible signal at $0.70 \mathrm{~V} / \mathrm{ECS}$ with a peak-to-peak separation $\Delta \mathrm{Ep}=15-17 \mathrm{mV}$ while a quasireversible signal is usually obtained at bare GCE (Fig. 2A). In addition, the current intensity at bare GCE is much lower $(\mathrm{Ipa}=0.4 \mu \mathrm{A})$ than those obtained at GCE/ERGO (Ipa = 5.6 $\mu \mathrm{A})$, indicating an enhanced sensitivity for SY detection. Note that the capacitive currents were gradually increased following the number of CV scans, leading to an almost similar value of the faradic peak current intensity for all the ERGO-modified electrodes. Since DPV measurements are not sensitive to capacitive currents, the DPV signal intensity of SY increases following the number of CV scans in the electrodeposition process of ERGO, $5 \mathrm{CVs}<10 \mathrm{CVs}<15$ CVs (Fig. 2B) in agreement with the increase of ECSA as shown above.

Based on these results, it could be concluded that using 15 CVs for electrodeposition process has led to GCE/ERGO 
electrode with the highest practical sensitivity. ERGO/GCE electrodes prepared with $15 \mathrm{CV}$ scans were then used in the following.
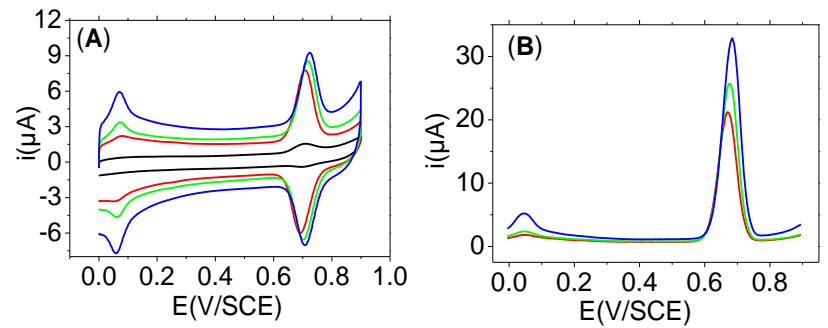

Fig. 2. Electrochemical response of $10 \mu \mathrm{M} \mathrm{SY}$ at GCE/ERGO in $\mathrm{pH}=5$ acetate buffer (A) CVs at $\mathrm{v}=50 \mathrm{mV} \cdot \mathrm{s}^{-1}$ (B) DPV (step potential $\mathrm{Es}=5 \mathrm{mV}$, pulse potential $\mathrm{Ep}=40 \mathrm{mV}$, pulse width tp $=200 \mathrm{~ms}$, scan rate $10 \mathrm{mV} \mathrm{s}^{-1}$, integration time Idt $=$ $90 \mathrm{~ms}$; accumulation times of 3 minutes at $0 \mathrm{~V}$ ). GCE/ERGO prepared with 5 (red line), 10 (green line) and 15 (blue line) CV scans. In (A), signal obtained at bare GCE (black line) for comparison purposes.

\subsection{Electrochemical properties of the SY onto GCE/ERGO surface}

\subsubsection{Effect of the $\mathrm{pH}$ value}

Effect of the $\mathrm{pH}$ value on the electrochemical answer of SY was firstly investigated by varying the $\mathrm{pH}$ from 3 to 8 using both acetate and phosphate buffer solutions. As shown in Fig. 3 ., the intensity of the peak currents (Ipa and Ipc) gradually increases from $\mathrm{pH} 3$ to 5 and decreases from 5 to 8 (Fig. 3A). Therefore, a maximum Ipa (and Ipc) value is obtained with pH 5 acetate buffer solution, which is selected for further investigation. In addition, both anodic and cathodic peak potentials are negatively shifted with increase of $\mathrm{pH}$, suggesting that the oxidation mechanism of SY involves protons exchange along with electron transfers. A linear relationship is found between the anodic peak potential Epa and $\mathrm{pH}$ with a slope equal to $-0.029 \mathrm{~V}$ per $\mathrm{pH}$ unit (Fig. 3B). Similar behaviors have been reported in the literature data $[20,21,34,48,50,50,53,54,55,56,57]$. Such a value is half of the theoretical Nernstian value of $0.059 \mathrm{mV} \cdot \mathrm{pH}^{-1}$ and indicates that the ratio of protons to electrons involved in the oxidation pathway is equal to 0.5 .
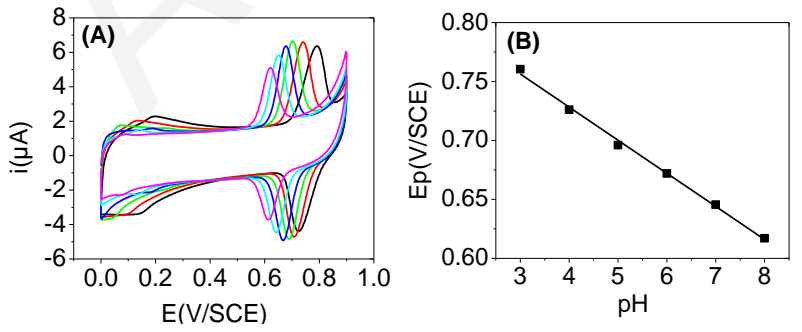

Fig. 3. (A) CVs at $\mathrm{v}=50 \mathrm{mV} \cdot \mathrm{s}^{-1}$ of $10 \mu \mathrm{M} \mathrm{SY}$ at a GCE/ERGO electrode in acetate or phosphate buffer solutions with different $\mathrm{pH}$ values, $\mathrm{pH}=3$ (black), $\mathrm{pH}=4$ (red), $\mathrm{pH}=5$ (green), $\mathrm{pH}=6$ (blue), $\mathrm{pH}=7$ (cyan), $\mathrm{pH}=8$ (magenta). (B) Linear variation of the anodic peak potential as a function of the $\mathrm{pH}$ value.

\subsubsection{Effect of the scan rate}

To further investigate the electrochemical oxidation process of SY at GCE/ERGO, a series of CVs was recorded in a pH 5 acetate buffer solution with different scan rates (v) in the range $0.02-1.0 \mathrm{~V} . \mathrm{s}^{-1}$ (Fig. 4Error! Reference source not found.A). The intensities of the anodic and the cathodic peak current are linearly proportional to the scan rates in the studied range, showing that the oxidation of SY is an adsorption-controlled process (Fig. 4B). Upon increasing the scan rate, the anodic and cathodic peak potentials start to broaden and shift to positive and negative directions with respect to formal apparent potential $\mathrm{E}^{\circ}$. This behavior is connected to the kinetics of the electrochemical process. Indeed, the application of a large overpotential is required to keep a sufficient flux of electrons to be transferred to the electrode since the timescale of the CVs experiments (RT/Fv) decreases to a point to become comparable to the electron transfer kinetics. By using the Laviron's formalism, which is based on the classical Butler-Volmer theory, 58 the peak potential values were plotted against the logarithm of the scan rate (lnv), leading to two linear regions for each cathodic and anodic potentials, respectively (Fig. 4C). The intercept of these lines $\left(\mathrm{v}_{\mathrm{i}}\right)$ allows a determination of the apparent electron transfer rate kinetic rate constant $\left(\mathrm{k}_{\mathrm{ET}}\right)$ following Eq. 2.

$$
\mathrm{k}_{\mathrm{ET}}=(1-\alpha) \mathrm{nFv}_{\mathrm{i}} / \mathrm{RT} \quad \text { (Eq. 2) }
$$

where $\mathrm{n}$ is the number of exchanged electrons, $\mathrm{F}$ is Faraday' constant, $\mathrm{R}$ the universal gas constant, $\mathrm{T}$ is temperature $(293 \mathrm{~K})$ and $v_{i}$ is the intercept of the linear regions in the Ep-lnv plots.

The slopes for the linear region at higher scan rates are equal to RT/(1- $\alpha) n F$ and $-\mathrm{RT} / \alpha \mathrm{nF}$ for the anodic and cathodic processes, respectively. From these slopes values, we could estimate that $\alpha$ and $n$ are equal to 0.5 and 2 , respectively. It comes a value of $6.3 \mathrm{~s}^{-1}$ for $\mathrm{k}_{\mathrm{ET}}$.

The oxidation mechanism of SY at GCE/ERGO involves one proton and two electrons. This result falls in line with a recent paper that thoroughly investigates the electrochemical oxidation pathway of SY by combining theoretical calculations and spectroelectrochemical analyses [59].

\subsection{Optimisation of DPV parameters for SY detection}

DPV technique is proposed for SY determination due to its high sensitivity and ease of operation. The DPV parameters including Es (step potential) ts (pulse width), Ep (pulse amplitude), tp (sample period) and Idt (integration time) were firstly investigated using $0.5 \mu \mathrm{M} \mathrm{SY}$ in a $\mathrm{pH} 5$ acetate buffer 
solution while an accumulation time of $2 \mathrm{~min}$ at a potential of $0 \mathrm{~V} / \mathrm{SCE}$ was maintained. The results demonstrated that the maximum DPV response could be obtained with optimized experimental parameters including scan rate $\mathrm{v}=35 \mathrm{mV} \cdot \mathrm{s}^{-1}$; Es = $10.5 \mathrm{mV}$; ts = $300 \mathrm{~ms} ; \mathrm{Ep}=20 \mathrm{mV}$, tp = $120 \mathrm{~ms}$; time of integration Idt $=60(\mathrm{~ms})$ (see Electronic Supplementary Material Fig. S5, S6 and S7).
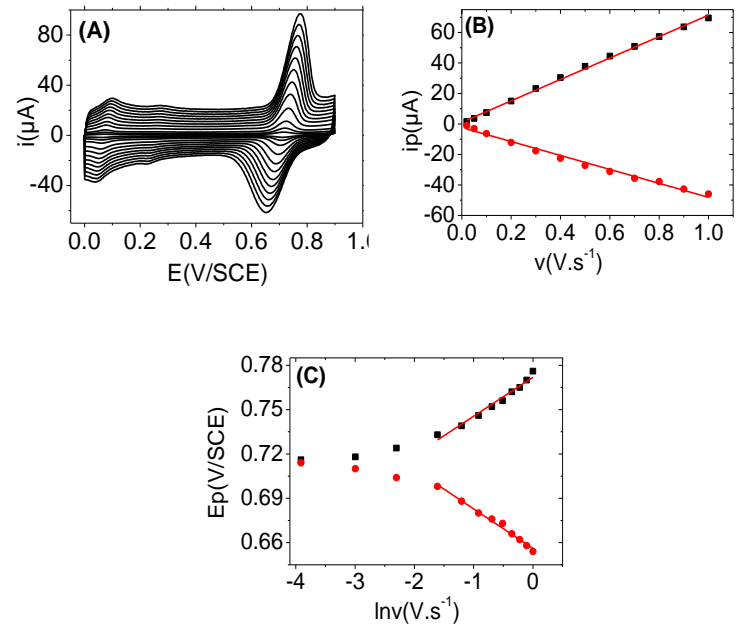

Fig. 4. (A) CVs of $10 \mu \mathrm{M} \mathrm{SY}$ in a pH 5 acetate buffer solution at the GCE/ERGO surface at scan rates varying from 20 to $1000 \mathrm{mV} \mathrm{s}^{-1}$; (B) Plot of the intensity of the anodic (O) and cathodic (ם) peak currents Ip against scan rate v (V.s $\left.{ }^{-1}\right)$; (C) Plot of the anodic $(\boldsymbol{\square})$ and cathodic $(\bullet)$ peak potential Ep (V) against $\operatorname{lnv}\left(\mathrm{v}, \mathrm{V} . \mathrm{s}^{-1}\right)$.

Since the electrochemical process involves the adsorption of SY onto GCE/ERGO surfaces, the effect of accumulation time along with the effect of the potential value employed for the accumulation step need to be investigated. The DPV measurements show that SY response was significantly increased following the accumulation times from 0 to $3 \mathrm{~min}$ (Fig. 5A and see Electronic Supplementary Material Fig. S8). The SY signal was increased by $140 ; 200$ and $265 \%$ corresponding to one; two and three min of accumulation. This result suggests that GCE/ERGO surfaces exhibited a high adsorption capacity. Finally, we consider that 2 min of accumulation time is an acceptable duration, leading to a good response and thus was used for further measurements. Considering the effect of potential values, SY response was found to be almost independent to accumulation potential as shown in Fig. 5B. Therefore, the potential at $0 \mathrm{~V}$ was used as an accumulation potential for SY determination.
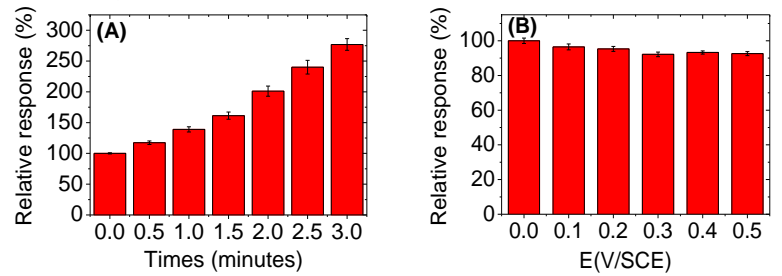

Fig. 5. (A) Relative intensity of DPV signal with an accumulation potential at $0 \mathrm{~V}$ for different accumulation times. Intensity of the signal with no accumulation time is taken as a reference. (B) Relative intensity of DPV signal using 2 minutes of accumulation for different potential values. Intensity of the signal at $0 \mathrm{~V}$ is taken as a reference. Error bars represent the standard deviation for triple measurements.

\subsection{Calibration curve and detection limit for SY detection}

DPV measurements using the GCE/ERGO electrodes were performed at different SY concentrations from 50 to $1000 \mathrm{nM}$ in acetate buffer $(\mathrm{pH}=5)$ (Fig. 6A). It was observed that SY response regularly increases as a function of SY concentration, following a linear equation $\operatorname{Ip}(\mu \mathrm{A})=$ $0.0083^{*} \mathrm{C}(\mathrm{nM})-0.40\left(\mathrm{R}^{2}=0.994\right)$ (Fig. 6B). The limit of detection (LOD) was estimated to be $19.2 \mathrm{nM}$ from linear regression in a limited range from 50 to $350 \mathrm{nM}$ following Eq. 3 [60].

$$
\mathrm{LOD}=3 \mathrm{Sy} / \mathrm{b} \quad(\mathrm{Eq} .3)
$$

where Sy is the standard deviation of the response and $b$ is the slope of the calibration curve for a limited range from 50 to $100 \mathrm{nM}$.
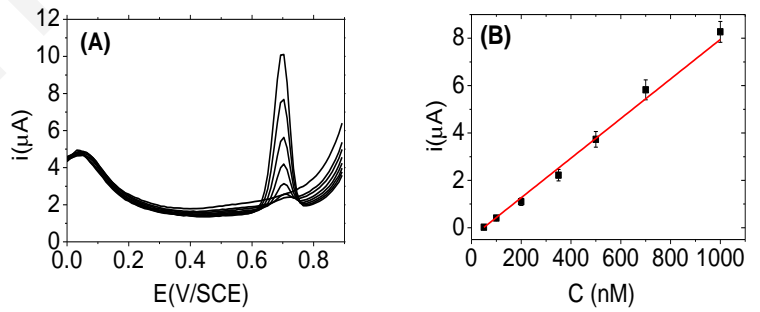

Fig. 6. (A) DPV of SY at different concentrations from $50-$ $1000 \mathrm{nM}$, namely 50, 100, 200, 350, 500, 700, $1000 \mathrm{nM}$. (B) Plot of the current intensity in the DPV response towards SY concentration. Optimized DPV conditions: scan rate $\mathrm{v}=35$ $\mathrm{mV} . \mathrm{s}-1$, Es $=10.5 \mathrm{mV}$, ts $=300 \mathrm{~ms}, \mathrm{tp}=120 \mathrm{~ms}$, Idt $=60 \mathrm{~ms}$ and $\mathrm{Ep}=20 \mathrm{mV}$, accumulation time of 2 minutes at $0 \mathrm{~V} / \mathrm{SCE}$.

The comparison of GCE/ERGO with some other type of materials modified GCE electrodes for SY determination are typically summarized in Table 1 . It could be observed that the GCE/ERGO electrochemical sensor developed in this work exhibits good performance for SY detection with an acceptable detection limit when compared to other previously described systems. For practical applications, low detection limit might not be a critical point for real sample analysis since the typical amount of SY in food sample, notably in beverages is rather high. However, considering that human health and food safety regulations tend to be more stringent, the detection of SY in a more sensitive manner could become of importance. 
Table 1. Performance of different modified electrodes for SY detection

\begin{tabular}{cccc}
\hline Electrode & $\begin{array}{c}\text { Linear range } \\
(\mathrm{nM})\end{array}$ & $\begin{array}{c}\text { Detection } \\
\text { limit }(\mathrm{nM})\end{array}$ & Reference \\
\hline Au/rGO/GCE & $2-110000$ & 2 & 50 \\
PLPA/GCE & $400-14010$ & 40 & 61 \\
Poly(L- & $8-700$ & 4 & 20 \\
Cysteine)/GCE & & 1.5 & 54 \\
Au- & $686-$ & & \\
Pd/rGO/GCE & 331000 & 22 & 62 \\
MWCNT/GCE & $55-11000$ & 4.2 & 63 \\
CTAB- & $80-10000$ & 0.7 & 23 \\
Gr/Pt/GCE & & & \\
CTAB-MMT- & $2.5-200$ & 2.16 & 48 \\
Ca/GCE & & 66 & 64 \\
GN-Ni/GCE & $7.37-442$ & & \\
Chitosan- & $200-$ & 1800 & 57 \\
graphene/GCE & 100000 & & \\
Gr/GCE & $1000-$ & 0.5 & 65 \\
& 100000 & 19.2 & This \\
ERGO/SPE & $10-20000$ & & work \\
ERGO/GCE & $50-1000$ & & \\
\hline GCE glassy & & & \\
\hline
\end{tabular}

GCE: glassy carbon electrode; rGO: reduced graphene oxide; PLPA: poly-L-phenylalanine; MWCNT: multi-walled carbon nanotube; CTAB-Gr: hexadecyltrimethyl bromide functionalized graphene; CTAB-MMT-Ca: hexadecyltrimethyl bromide functionalized montmorillonite; ERGO: electrochemically reduced graphene oxide; GN: graphene; SPE:screen-printed carbon electrode

An important point is the fact that our GCE/ERGO sensor which is prepared through a very simple strategy incorporates only one component, in sharp contrast with many other systems. In this connection, we found two other interesting sensing examples for SY detection only based on GCE modified with ERGO [57,65]. Interestingly, the performance our GCE/ERGO compares well with these two examples but exhibits a higher sensitivity equal to $9 \mu \mathrm{A} / \mu \mathrm{M}$ compared to $0.79 \mu \mathrm{A} / \mu \mathrm{M},[65]$ and $0.017 \mu \mathrm{A} / \mu \mathrm{M},[57]$ respectively. Actually, the sensitivity toward SY of the sensor developed in this work is of the highest reported ones [21,48,66]. The LOD shows very good result compared to those estimated in references, [57,65] especially since LOD at ERGO/SPE might be probably overestimated regarding reported detection DPV curves.[65]

\subsubsection{Repeatability, storage stability and reusability}

The reliability of this sensor is evaluated by repetitive experiments $(\mathrm{n}=7)$ in $\mathrm{pH}=5$ acetate buffer solution containing $0.5 \mu \mathrm{M}$ SY (see Electronic Supplementary Material Fig. S9). The RSD value is calculated to be $2.13 \%$, demonstrating the high reliability of the assay. The electrochemical sensor was then stored in $\mathrm{pH} 5$ buffer at room temperature conditions for stability measurements. The DPV measurements showed no change of the signal after $24 \mathrm{~h}$ and only a slight decrease of $15 \%$ after 48 hours (see Electronic Supplementary Material Fig. S10). The electrochemical sensor could be efficiently regenerated through a simple potential cycling ( 5 cycles) in $0.5 \mathrm{M}$ aqueous $\mathrm{H}_{2} \mathrm{SO}_{4}$ solution. The response of the electrochemical sensor exhibited no significant change (below of $3.5 \%$ ) after 5 successive measurement/cleaning cycles (see Electronic Supplementary Material Fig. S11), showing its high reusability.

\subsubsection{Interference}

The anti-interference ability of the GCE/ERGO sensors was also evaluated taking into account of the potential presence of ingredients or food additives such as sweeteners or preservatives. The DPV responses of a standard solution of SY $(0.5 \mu \mathrm{M}$ in $\mathrm{pH} 5$ acetate buffer) were studied after addition 100 -fold concentration of $\mathrm{KCl}, \mathrm{NaCl}, \mathrm{CaCl}_{2}$, glucose, sodium citrate and ascorbic acid (AA). There is no obvious influence of these interfering species since the DPV signal variations were below $5 \%$ of the initial SY response without interferences (Fig. 7).

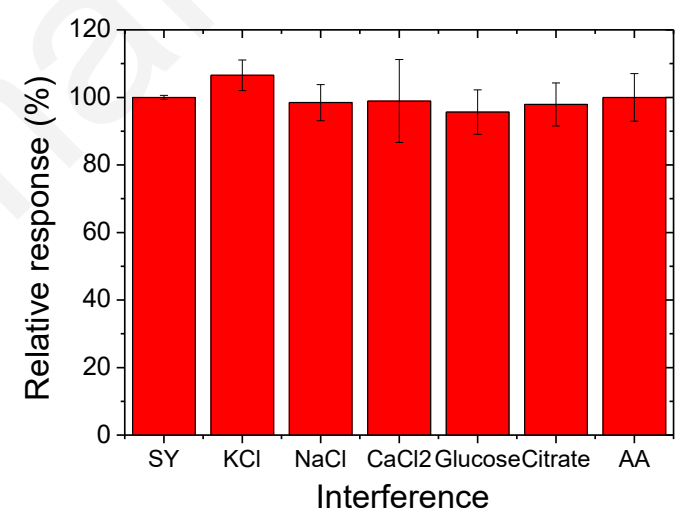

Fig. 7. Response of the sensor towards SY detection $(0.5 \mu \mathrm{M})$ in $\mathrm{pH} 5$ buffer with the addition of 100-folds concentration of interferences. Error bar represents the SD of triple measurements.

\subsubsection{Real Sample analysis}

For evaluating its potential application, the ERGO/GCE sensor was applied to the detection of SY in real samples of soft drinks collected from a local market, namely Sting, Samurai, Number 1 and Mirinda. We carried out DPV measurements under optimized experimental conditions. A very small volume (less than $15 \%$ of total volume of solution) of sample ( $60 \mu \mathrm{L}$ of Samurai, $16 \mu \mathrm{L}$ of Mirinda, 8 $\mu \mathrm{L}$ of Number 1 and $40 \mu \mathrm{L}$ of Sting) was added directly to the pH 5 acetate buffer solution ( $5 \mathrm{~mL}$ ) (Fig. 8). 


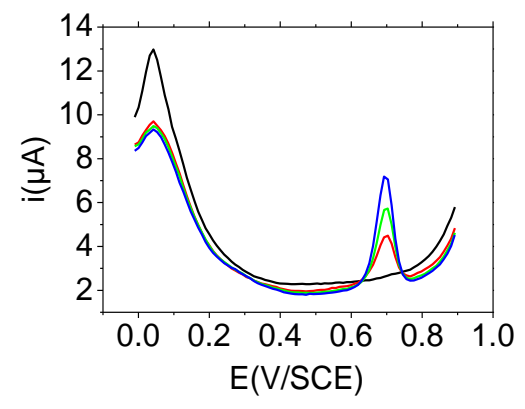

Fig. 8. DPV at GCE/ERGO electrochemical sensor for analysis of Samurai sample: DPV conditions: Es $=10.5 \mathrm{mV}$; ts $=300 \mathrm{~ms} ; \mathrm{Ep}=20 \mathrm{mV} ; \mathrm{tp}=120 \mathrm{~ms} ;$ Idt $=60 \mathrm{~ms}$; accumulation time of 2 minutes at $0 \mathrm{~V} / \mathrm{SCE}$. Before (black line) and after addition of $60 \mu \mathrm{L}$ of Sting (red line) followed by addition of $150 \mathrm{nM}$ of SY (green line), of $350 \mathrm{nM}$ of SY (blue line).
To evaluate the accuracy of the sensor, known amounts of SY were spiked into samples, leading to an increase of the intensity of the DPV response. These observations clearly demonstrate that such sensor could enable identification of the presence of SY in the drink. Each sample undergoes 7 detection rounds and results are gathered in Table 2. The RSD is acceptable, indicating that the precision of the sensor is good. The recoveries were then tested, and values in the range 93.35 to $107.7 \%$ indicate that the method possesses good accuracy.

HPLC method was also used to determine the concentration of SY in the soft drink samples and the results are given in Table 2. From the comparison of HPLC method and the ERGO/GCE electrochemical detection, it can be seen that the two methods lead to very similar results, with a small relative variation. Thus the fabricated ERGO/GCE sensor has a very good potential for monitoring SY in real samples with a low cost, simple preparation and good accuracy.

Table 2. Determination of SY in soft drinks samples by electrochemical detection at ERGO/GCE and by HPLC

\begin{tabular}{cccccccc}
\hline Sample & $\begin{array}{c}\text { Added } \\
(\mathrm{nM})\end{array}$ & $\begin{array}{c}\text { Expected } \\
(\mathrm{nM})\end{array}$ & $\begin{array}{c}\text { Found } \\
(\mathrm{nM})\end{array}$ & $\begin{array}{c}\text { RSD } \\
(\%)\end{array}$ & $\begin{array}{c}\text { Recovery } \\
(\%)\end{array}$ & $\begin{array}{c}\text { By HPLC } \\
(\mathrm{nM})\end{array}$ & $\begin{array}{c}\text { Relative error } \\
(\%)\end{array}$ \\
\hline Samurai & - & - & 292.65 & 5.63 & - & 307.56 & -4.85 \\
& 150 & 457.56 & 439.85 & 0.88 & 96.13 & & \\
& 200 & 657.56 & 613.85 & 2.05 & 93.35 & & \\
Mirinda & - & - & 353.77 & 4.85 & - & 406.36 & -12.94 \\
& 150 & 556.36 & 538.34 & 6.47 & 96.76 & & \\
& 200 & 756.36 & 814.64 & 4.54 & 107.70 & & \\
Sting & - & - & 264.99 & 4.37 & - & 292.06 & -9.27 \\
Number 1 & - & - & 161.85 & 5.24 & & 171.5 & -5.63 \\
\hline
\end{tabular}

\section{Conclusion}

Accurate, rapid and highly sensitive titration of Sunset Yellow could be performed at a GCE electrode modified with graphene materials. This work proposes a simple and effective route for preparing GCE/ERGO sensors directly from graphite flakes, allowing the development of low-cost electrochemical devices. Electrochemical reduction of exfoliated graphite enables reduction of GO in to reduced GO and deposition onto GCE surface. The result also indicates that thickness and electron transfer properties of the ERGO layer could be easily controlled by means of the $\mathrm{CV}$ scan numbers. The modified GCE/ERGO preparing from $15 \mathrm{CVs}$ scans exhibited higher surface area and larger sensitivity toward SY detection than those prepared with 5 or 10 scans. The resulting sensor demonstrated a high performance for SY determination with a low detection limit of $19.2 \mathrm{nM}$ and a high sensitivity of $9 \mu \mathrm{A} / \mu \mathrm{M}$, high reliability and a successful practical applicability for SY analysis in real samples. Furthermore, this sensor could be easily cleaned and reused even after measurement in real samples. The ERGO/GCE sensing platform exhibits a high potential for developing a portable, reliable, rapid and low-cost on-site sensors for monitoring food colorants in foods or in environmental effluents.

Acknowledgement: The authors would like to thank Vietnam Academy of Science and Technology (VAST.CTG.08/16-18) the Vietnam National Foundation for Science and Technology Development (NAFOSTED) under grant number 104.06-2016.42 for funding support. We thank also Mr. Van Nhan LE for performing HPLC measurements and fruitful discussions on sunset yellow determination.

Conflict of interest: The authors declare that they have no conflict of interest.

\section{References}


[1]Thune P, Granholt A, Provocation tests with antiphlogistica and food additives in recurrent urticarial, Dermatologica 1975;151:360-7. DOI:10.1159/000251361

[2] Shari SL, Fowler Jr JF, Contact anaphylaxis: a review, American Journal of Contact Dermatitis 1995;6:133-142.

[3] Koutsogeorgopoulou L, Maravelias C, Methenitou G, Koutselinis A, Immunological aspects of the common food colorants, amaranth and tartrazine, Veterinary and Human Toxicology 1998;40:1-4.

[4]Yadav A, Kumar A, Dwivedi PD, Tripathi A, Das M, In vitro studies on immunotoxic potential of orange II in splenocytes, Toxicology Letters 2012;208:239-245

[5] Srivinivasan GP, Sikkanthar A, Elamaran A, Delma, K, Subramaniyam CR, Somasundaran ST, Biodegradation of carcinogetic textile azo dye using bacterial isolates of mangrove sediment, J. Coast. Life Med. 2014;2:154-162.

[6] Arnold LE, Lofthouse N, Hurt E, Artificial food colors and attention-deficit/hyperactivity symptoms: conclusions to dye for, Neurotherapeutics 2012 ; 9 599-609

[7] Reconsideration of the temporary ADI and refined exposure assessment for Sunset Yellow FCF (E 110), EFSA Journal http://doi.org/10.2903/j.efsa.2014.3765

[8] Llamas NE, Garrido M, Di Nezio MS, Band BSF, Second order advantage in the determination of amaranth, sunset yellow FCF and tartrazine by UV-vis and multivariate curve resolution-alternating least squares, Anal. Chim. Acta 2009;655:38-42

[9] Yuan Y, Zhao X, Qiao M, Zhu J, Liu S, Yang J, Hu X, Determination of sunset yellow in soft drinks based on fluorescence quenching of carbon dot, Spectrochim. Acta A 2016;167:106-110

[10] Zeynali K., Manafi-Khoshmanesh S, Simultaneous spectrophotometric determination of sunset yellow and quinoline yellow in a single step, J. Chin. Chem. Soc. 2015;62:772-9

[11] Zhu Y, Zhang L, Yang L, Designing of the functional paper-based surface-enhanced raman spectroscopy substrates for colorants detection, Mater. Res. Bull. 2015;63:199-204

[12] Alves SP, Brum DM, Branco de Andrade ÉC, Pereira Netto AD, Determination of synthetic dyes in selected foodstuffs by high performance liquid chromatography with UV-DAD detection, Food Chem. 2008 ;107:489-496

[13] Sha O, Zhu X, Feng Y, Ma W, Determination of Sunset Yellow and Tartrazine in Food Samples by Combining Ionic Liquid-Based Aqueous Two-Phase System with High Performance Liquid Chromatography, J. Anal. Meth. Chem. 2014. http://doi.org/10.1155/2014/964273

[14] Branch D, Sciences M, Sunset yellow, tartrazine and sodium benzoate in orange juice distributed in Iranian market and subsequent exposure assessment, Inter. Food. Res. J. 2018;25:975-981.
[15] Alp H, Bas D, Yas A, Yaylı N, Ocak M, Simultaneous Determination of Sunset Yellow FCF, Allura Red AC, Quinoline Yellow WS, and Tartrazine in Food Samples by RP-HPLC, Journal of Chemistry 2018. https://doi.org/10.1155/2018/6486250

[16] Zou T, He P, Yasen A, Li Z, Determination of seven synthetic dyes in animal feeds and meat by high performance liquid chromatography with diode array and tandem mass detectors, Food Chem. 2013;138:1742-8

[17] Niu X, Lan M, Zhao H, Chen C, Highly Sensitive and Selective Nonenzymatic Detection of Glucose Using ThreeDimensional Porous Nickel Nanostructures, Anal. Chem. 2013;85: 3561-9

[18] Moghimi N, Leung KT, FePt Alloy Nanoparticles for Biosensing: Enhancement of Vitamin C Sensor Performance and Selectivity by Nanoalloying, Anal. Chem. 2013;85:59745980

[19] Vladislav N, Buzuk M, Rončević IŠ, Brinić S, Electroanalytical Methods for Determination of Sunset Yellow - a Review, Int. J. Electrochem. Sci. 2018; 13:70087019

[20] Zhang K, Luo P, Wu J, Wang W, Ye B, Highly sensitive determination of Sunset Yellow in drink using a poly (1cysteine) modified glassy carbon electrode, Anal. Methods, 2013;5:5044-5050

[21] Wang M, Sun Q, Gao Y, Yang X, Zhao J, Determination of Sunset yellow in foods based on a facile electrochemical sensor, Anal. Methods $2014 ; 6: 8760-8766$

[22] Królicka A, Bobrowski A, Zareogonekbski J, Tesarowicz I, Bismuth film electrodes for adsorptive stripping voltammetric determination of sunset yellow FCF in soft drinks, Electroanalysis 2014;26:756-765

[23] Songyang Y, Yang X, Xie S, Hao H, Song J, Highlysensitive and rapid determination of sunset yellow using functionalized montmorillonite-modified electrode, Food Chem. 2015;173:640-4

[24] Ya Y, Jiang C, Li T, Liao J, Fan Y, Wei Y, Yan F, Xie $\mathrm{L}$, A zinc oxide nanoflower-based electrochemical sensor for trace detection of sunset yellow, Sensors 2017;17:1-9

[25] Perez-Lopez B, Merkoc A, Nanomaterials based biosensors for food analysis applications, Trends Food Sci. Technol. 2011 22:625-639

[26] Marty J, Vasilescu A, Hayat A, Ga S, Advantages of Carbon Nanomaterials in Electrochemical Aptasensors for Food Analysis, Electroanalysis 2018;30:2-19

[27] Mishra GK, Barfidokht A, Tehrani F, Mishra RK, Food Safety Analysis Using Electrochemical Biosensors, Foods 2018;7:141-151

[28] Maduraiveeran G, Jin W, Nanomaterials based electrochemical sensor and biosensor platforms for 
environmental applications Trends in Environmental Anal. Chem. $2017 ; 13: 10-23$

[29] Shao Y, Wang J, Wu H, Liu J, Aksay IA, Lin Y, Graphene based electrochemical sensors and biosensors: A review, Electroanalysis 2010;22:1027-1036

[30] Rowley-Neale SJ, Randviir EP, Abo Dena AS, Banks $\mathrm{CE}$, An overview of recent applications of reduced graphene oxide as a basis of electroanalytical sensing platforms, Appl. Mater. Today $2018 ; 10: 218-226$

[31] Wang Y, Li Y, Tang L, Lu J, Li J, Application of graphene-modified electrode for selective detection of dopamine, Electrochem. Commun. 2009;11:889-892

[32] Chan KF, Lim HN, Shams N, Jayabal S, Pandikumar A, Huang NM, Fabrication of graphene/gold-modified screenprinted electrode for detection of carcinoembryonic antigen, Mater. Sci. Eng. C. 2016;58 :666-674

[33] Pumera M, Ambrosi A, Bonanni A, Chng ELK, Poh HL, Graphene for electrochemical sensing and biosensing, TrAC - Trends Anal. Chem. 2010;29:954-965

[34] Wang M, Zhao J, Facile synthesis of Au supported on ionic liquid functionalized reduced graphene oxide for simultaneous determination of Sunset yellow and Tartrazine in drinks, Sensors Actuators B Chem. 2015;216:578-585

[35] Zhang Y, Xiao X, Sun Y, Shi Y, Dai H, Ni P, Hu J, Li Z, Song Y, Wang L, Electrochemical deposition of nickel nanoparticles on reduced graphene oxide film for nonenzymatic glucose sensing, Electroanalysis 2013;25:959966

[36] Zhou ., Wang Y. Zhai Y, Zhai J. Ren W, Wang F. Dong $\mathrm{S}$, Controlled synthesis of large-area and patterned electrochemically reduced graphene oxide films, Chem. - A Eur. J. 2009;15:6116-6120

[37] Shao Y, Wang J., Engelhard M., Wang C., Lin Y., Facile and controllable electrochemical reduction of graphene oxide and its applications, J. Mater. Chem. 2010;20:743-8

[38] Guo H, Wang X, Qian Q, Wang F, Xia X, A Green Approach to the Synthesis of graphene nanosheet ACS Nano 2009;3:2653-9

[39] Báez D, Pardo H, Laborda I, Marco J, Yáñez C, Bollo S, Reduced Graphene Oxides: Influence of the Reduction Method on the Electrocatalytic Effect towards Nucleic Acid Oxidation, Nanomaterials 2017;7:168-182

[40] Wang C, Du J, Wang H, Zou C, Jiang F, Yang P, Du Y, A facile electrochemical sensor based on reduced graphene oxide and Au nanoplates modified glassy carbon electrode for simultaneous detection of ascorbic acid, dopamine and uric acid, Sens. Actuators B Chem. 2014;203:302-9

[41] Chen L, Tang Y, Wang K, Liu C, Luo S, Direct electrodeposition of reduced graphene oxide on glassy carbon electrode and its electrochemical application, Electrochem. Commun. 2011;13:133-7
[42] Asadian E, Shahrokhian S, Iraji Zad A, GhorbaniBidkorbeh F, Glassy carbon electrode modified with 3D graphene-carbon nanotube network for sensitive electrochemical determination of methotrexate, Sens. Actuators B Chem. 2017;239:617-627

[43] Zhang Y, Zhang M, Wei Q, Gao Y, Guo L, Al-Ghanim KA, Mahbooh S, Zhang X, An Easily Fabricated Electrochemical Sensor Based on a Graphene-Modified Glassy Carbon Electrode for Determination of Octopamine and Tyramine, Sensors 2016;16:535-548

[44] Xue Z, Yin B, Li M, Rao H, Wang H, Zhou X, Liu X, Lu $X$, Direct electrodeposition of well dispersed electrochemical reduction graphene oxide assembled with nickel oxide nanocomposite and its improved electrocatalytic activity toward 2, 4, 6-Trinitrophenol, Electrochim. Acta. 2016;192:512-520

[45] Yang B, Wang H, Du J, Fu Y, Yang P, Du Y, Direct electrodeposition of reduced graphene oxide on carbon fiber electrode for simultaneous determination of ascorbic acid, dopamine and uric acid, Colloids Surf. A Physicochem. Eng. Asp. 2014;456:146-152

[46] Lee CS, Yu S, Kim T, One-Step Electrochemical Fabrication of Reduced Graphene Oxide/Gold Nanoparticles Nanocomposite-Modified Electrode for Simultaneous Detection of Dopamine, Ascorbic Acid, and Uric Acid, Nanomaterials, 2017;8:17-19

[47] Yang J, Yu JH, Rudi Strickler J, Chang WJ, Gunasekaran $S$, Nickel nanoparticle-chitosan-reduced graphene oxidemodified screen-printed electrodes for enzyme-free glucose sensing in portable microfluidic devices, Biosens. Bioelectron. 2013;47:530-8

[48] Gan T, Sun J, Wu Q, Jing Q, Yu S, Graphene decorated with nickel nanoparticles as a sensitive substrate for simultaneous determination of sunset yellow and tartrazine in food samples, Electroanalysis 2013 ;25:1505-1512

[49] Gan T, Sun J, Cao S, Gao F, Zhang Y, Yang Y, One-step electrochemical approach for the preparation of graphene wrapped-phosphotungstic acid hybrid and its application for simultaneous determination of sunset yellow and tartrazine, Electrochim. Acta. 2012;74:151-7

[50] Wang J, Yang B, Wang H, Yang P, Du Y, Highly sensitive electrochemical determination of Sunset Yellow based on gold nanoparticles/graphene electrode, Anal. Chim. Acta. 2015;893:41-8

[51] Marcano D.C., Kosynkin D.V., Berlin J.M., Sinitskii A., Sun Z., Slesarev A., Alemany L.B., Lu W., Tour J.M., Improved Synthesis of Graphene Oxide, ACS Nano 2010;4:183-191

[52] Yu H, Zha B, Chaoke B, Li R, Xing R, High-efficient Synthesis of Graphene Oxide Based on Improved Hummers Method, Sci. Rep. 2016;6:1-7 
[53] Majidi MR, Fadakar R, Baj B, Carbon Nanotube - Ionic Liquid (CNT-IL ) Nanocamposite Modified Sol-Gel Derived Carbon-Ceramic Electrode for Simultaneous Determination of Sunset Yellow and Tartrazine in Food Samples, Food Anal. Methods $2013 ; 6: 1388-1393$

[54] Wang J, Yang B., Zhang K., Bin D., Shiraishi Y., Yang P., Du Y., Highly sensitive electrochemical determination of sunset yellow based on the ultrafine $\mathrm{Au}-\mathrm{Pd}$ and reduced graphene oxide nanocomposites, J. Colloid Interface Sci. 2016; 481: 229-235

[55] Li L, Zheng H, Guo L, Qu L, Yu L, Construction of novel electrochemical sensors based on bimetallic nanoparticle functionalized graphene for determination of sunset yellow in soft drink, J. Electroanal. Chem. 2019;833:393-400

[56] Deng K, Li C, Li X, Huang H, Simultaneous detection of sunset yellow and tartrazine using the nanohybrid of gold nanorods decorated graphene oxide, J. Electroanal. Chem. 2016;780:296-302

[57] Pogacean F, Coros M, Mirel V, Magerusan ., BarbuTudoran L, Graphene-based materials produced by graphite electrochemical exfoliation in acidic solutions : application to sunset yellow voltammetric detection, Microchem. J. 2019;147:112-120

[58] Laviron E, General expression of the linear potential sweep voltammogram in the case of diffusion less electrochemical systems, J. Electronal. Chem. 1979 ;101: 1928

[59] Sierra-Rosales P, Berríos C, Squella JA, Experimental and theoretical insights into the electrooxidation pathway of azo-colorants on glassy carbon electrode, Electrochim. Acta 2018;290:556-567
[60] Shrivastava A, Gupta VB, Methods for the determination of limit of detection and limit of quantitation of the analytical methods, Chronides of young scientists 2011;2:21-5

[61] Chao MY, Ma XY, Convenient electrochemical determination of Sunset Yellow and tartrazine in food samples using a poly(L-phenylalanine)- modified glassy carbon electrode, Food Anal. Methods 2015;8:130-8 [62] Zhang W, Liu T, Zheng X, Huang W, Wan C, Surfaceenhanced oxidation and detection of Sunset Yellow and Tartrazine using multi-walled carbon nanotubes filmmodified electrode, Colloids Surf. B Biointerfaces 2009;74:28-31

[63] Yu L, Shi M, Yue X, Qu L, A novel and sensitive hexadecyltrimethyl ammonium bromide functionalized graphene supported platinum nanoparticles composite modified glassy carbon electrode for determination of sunset yellow in soft drinks, Sens. Actuators, B Chem. 2015;209:18

[64] Maguresan L, Pogacean F, Coros M, Socaci C, Pruneanu S, Leostan C, Pana IO, Green methodology for the preparation of chitosan/graphene nanomaterial through electrochemical exfoliation and its applicability in Sunset Yellow detection, Electrochim. Acta 2018;283:578-589 [65] Jampasa S, Siangproh W, Duangmal K, Chailapakul O, Electrochemically reduced graphene oxide-modified screenprinted carbon electrodes for a simple and highly sensitive electrochemical detection of synthetic colorants in beverages, Talanta 2016;160:113-124

[66] Gan T, Sun J, Meng W, Song L, Zhang Y, Electrochemical sensor based on graphene and mesoporous $\mathrm{TiO} 2$ for the simultaneous determination of trace colorants in food, Food Chem. 2013;141:3731-7 